\title{
Large Eddy simulation of the fluctuating wind environment at a bridge site in the mountainous area
}

\author{
Longfei Xing ${ }^{1}$, Mingjin Zhang ${ }^{1 *} \mathbb{D}$, Yongle Li ${ }^{1}$, Zhijie Zhang ${ }^{2}$ and Dianguo Yin ${ }^{3}$
}

\author{
*Correspondence: \\ zhang108119@163.com \\ 1 Department of Bridge \\ Engineering, Southwest \\ Jiaotong University, \\ 610031 Chengdu, Sichuan, \\ PR China \\ Full list of author information \\ is available at the end of the \\ article
}

\begin{abstract}
To have a comprehensive understanding of the complex wind environment at a bridge site in the mountainous area, a numerical simulation study of the wind environment under the mean and the fluctuating wind flow conditions was carried out and the results were compared. First, according to the weighted amplitude wave superposition (WAWS) method, the fluctuating wind speed time history was compiled by UDF. And the wind speed time history was added to the inlet boundary of a numerical empty wind tunnel to verify the feasibility of the simulation method of the fluctuating wind. Then, with a bridge in the mountainous area in Yunnan as the engineering background, a numerical simulation study of the wind environment of the bridge site area under the mean wind flow and the fluctuating wind flow was carried out by using FLUENT. The study indicates that Large Eddy Simulation (LES) method more accurate than Reynold average method with a sufficient number of grids and a short enough time step. The average wind characteristics of the bridge site under the mean wind and the fluctuating wind are not much different. The fluctuating wind characteristics at the bridge site are mainly affected by the terrain and the pulsating component of the wind flow. There are different terrain pulsation effects at the bridge site under different incoming flow directions.
\end{abstract}

Keywords: Bridge in mountain area, Wind environment of bridge site, Numerical simulation, fluctuating wind simulation, Large eddy simulation, Terrain pulsation effect

\section{Introduction}

Due to the complex terrain, the wind characteristics of the mountainous area are different from those of the plain area. The wind is one of the key factors to control the design of bridge construction, so the research on the wind environment in mountainous areas is very important. Field measurements, wind tunnel tests and numerical simulations are the main methods used to study the wind characteristics in mountain areas.

In field measurements, doing hard work, the widely used and well-known Davenport pulsating wind speed power spectrum was finally created (Davenport 1987). After long-term monitoring of the wind characteristics of high-rise structures in the typhoon area, the wind load characteristics of high-rise buildings in the typhoon have author(s) and the source, provide a link to the Creative Commons licence, and indicate if changes were made. The images or other third party material in this article are included in the article's Creative Commons licence, unless indicated otherwise in a credit line to the material. If material is not included in the article's Creative Commons licence and your intended use is not permitted by statutory regulation or exceeds the permitted use, you will need to obtain permission directly from the copyright holder. To view a copy of this licence, visit http:// creativecommons.org/licenses/by/4.0/. 
been studied (Li et al. 1998). Data collection is carried out by automatic weather station and other instruments, and the wind environment of the Dadu River is measured at the bridge site. The study found that the atmospheric circulation and high temperature difference are the main determinants of the design of the bridge. The gust factor and the surface roughness coefficient are relatively large if they are determined according to the specifications. (Li et al. 2014; Zhang and Li 2015).

In wind tunnel experiments, making the terrain model of the mountain area, the characteristics of the mountain wind environment under the uniform flow and the type B wind field were studied (Tang 2017). Through a large-scale terrain model test in the bridge site area, it is found that the shape of the wind profile at the location of the bridge tower is more consistent with the exponential law, and the wind attack angle at the bridge site in the mountainous area is also larger than that of the flat terrain (Li et al. 2017). By taking the mountainous area where the Xiangjiang River Bridge is located as the research object, the bridge site area was scaled to a scale of 1:500 to create a terrain model, and the setting of the transition section in the model was compared to the wind tunnel test of the terrain model (Liu et al. 2019).

In numerical simulations, the wind flow over a mountainous area in a region of $15.0 \mathrm{~km} \times 14.0 \mathrm{~km}$ was investigated by using computational fluid dynamics (CFD) method with a k- $\varepsilon$ turbulence model and a three-dimensional grid system (Maurizi et al. 1998). As the classical simulation methods, the wind characteristics of different forms of terrain models, such as the two dimensional hill model and the three dimensional step hill model, were simulated by the large-eddy simulations (LES) method (Iizuka and Kondo 2004; Tamura et al., 2007; Uchida and Ohya 2003). In addition, considering the effect of surface roughness, the LES method was used, and the results were compared with wind tunnel tests (Cao et al. 2012). Through the numerical simulation study of the complex topography of the bridge site area of the long-span bridge, it is found that the influence of the mountains on the wind environment at the bridge site is different under different flow directions, revealing the three-dimensional characteristics of the wind environment in the bridge site area (Li et al.,2011). The fluctuating time-history data satisfying the target wind filed were simulated with the weighted amplitude wave superposition (WAWS) to accurately simulate the inlet boundary conditions of turbulence information of Lager Eddy Simulation (LES) (Shen et al.2014). In order to increase the efficiency of the numerical simulation and reduce the error, a numerical simulation method was used to propose a method for determining the computational domain in the numerical simulation of mountainous terrain and the correctness of this method was proved (Zhang and Li 2015). The correctness of the numerical simulation method was also verified by comparing the results of the numerical simulation of the wind environment in the mountainous area with the field measured results at the bridge location (Liu et al.,2014). In order to resolve the difficulty in providing reasonable inlet boundary conditions for the numerical simulation of wind field in mountainous area, the multiscale coupling method was adopted for accurately simulating the wind field on the bridge site at mountainous area based on a meteorological software of weather research and forecast (WRF) (Shen et al. 2016). The simulation of natural convection was realized by adding momentum source terms to study the variation in wind field characteristics under the influence of thermal 
effects at a bridge site in a deep-cutting gorge with high altitude and temperature differences (Zhang et al. 2018).

The Tongyong Shidai community is chosen as the case study, and the wind environment influenced by high-rise building is analyze by large scale wind tunnel (Tang et al. 2020).

In this paper, taking a large-span suspension bridge in Yunnan mountainous area as the research object, and CFD method was used to simulate the wind characteristics of the bridge site. The average wind characteristics and fluctuating wind characteristics of the bridge site area under the fluctuating wind were studied, which provides a basis for improving the wind resistance design of the bridge. The main span of the bridge is $700 \mathrm{~m}$. The elevation of the bridge site area is raised from less than $300 \mathrm{~m}$ to more than $1800 \mathrm{~m}$. The terrain on one side of the bridge is flat and the terrain on the other side is steep. Figure 1 shows the layout of the bridge span.

\section{Large eddy simulation in fluctuating wind environment}

\subsection{Numerical model of empty wind tunnel}

A $5 \mathrm{~m} \times 4.5 \mathrm{~m} \times 25 \mathrm{~m}$ (width $\times$ height $\times$ length) empty wind tunnel model was created in FLUENT by using a full hexahedral structured grid. The height of the bottom grid is $0.02 \mathrm{~m}$. And the growth rate is 1.1. The total number of grids is 1.06 million, as shown in Fig. 2. The turbulence model used to simulate the fluctuating wind field is the LES (large eddy simulation) of the Smagorinsky subgrid-scale model. The discretized problem is numerically solved by using a SIMPLE pressure-velocity coupling algorithm. According to the amplitude wave superposition (WAWS) method, the fluctuating wind speed time history was compiled by UDF, and then it was used as the inlet boundary condition of the numerical wind tunnel. The time step is $0.005 \mathrm{~s}$. Since the place of interest is a certain distance from the ground of the computational domain, the grid height of the boundary layer has little influence on the calculation result. So, the $\mathrm{Y}+$ value is taken as 122 and the first layer height is $0.02 \mathrm{~m}$.

\subsection{Simulation result verification}

\subsubsection{The development of the fluctuating wind characteristics}

In order to verify the development of the fluctuating wind field characteristics in the computational domain and whether it can be consistent with the target value, a series of wind speed monitoring points were set up at the different height in the center of the model at $12 \mathrm{~m}$ and $24 \mathrm{~m}$ from the inlet. According to the wind speed of monitoring points, the average wind profile and turbulence intensity profile can be calculated and compared with the theoretical result, as shown in Figs. 3 and 4. It is obvious that the wind profiles at $12 \mathrm{~m}$ and $24 \mathrm{~m}$ from the inlet are in good agreement with the theoretical result. In addition, the simulation result shows that the turbulence intensity profile has a big difference from the theoretical value after the wind field flowed $12 \mathrm{~m}$. But after the wind field flowed $24 \mathrm{~m}$ in the computational domain, the turbulence intensity profile is basically the same as the theoretical result. This means that the simulation results will gradually approach the theoretical results with the flow distance increasing. Therefore, this fluctuating wind simulation method can simulate the average wind characteristics and fluctuating characteristics of the fluctuating wind relatively well. 



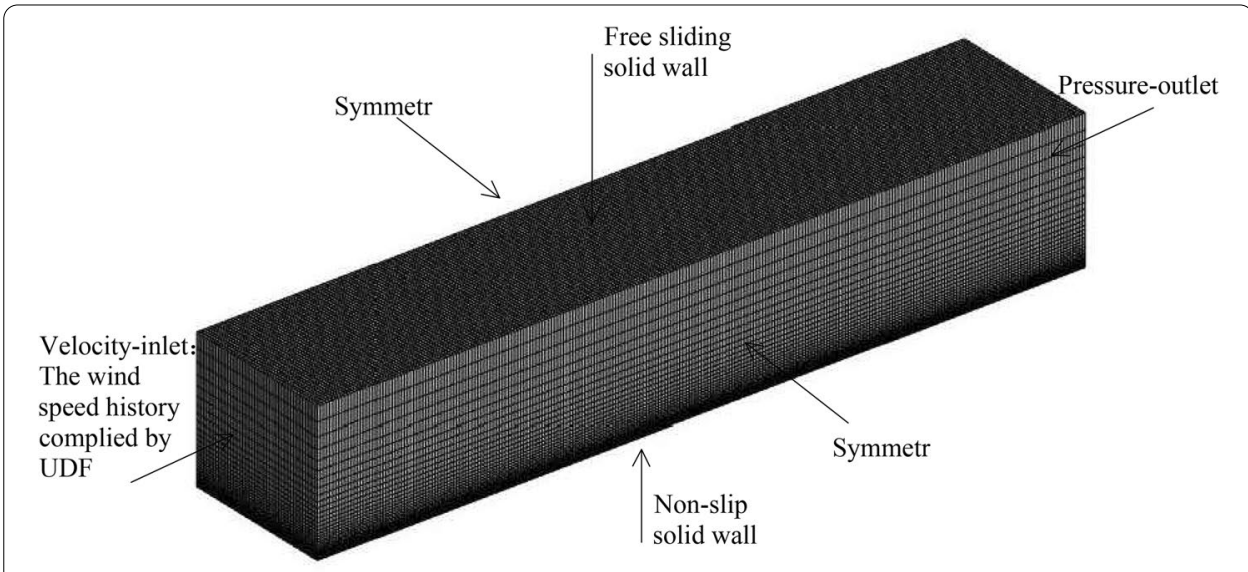

Fig. 2 Numerical model and boundary conditions of empty wind tunnel

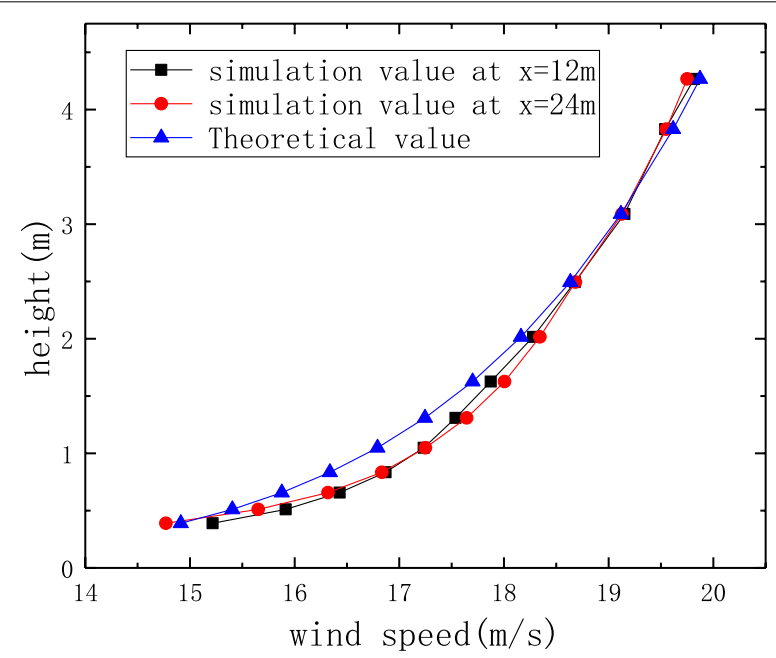

Fig. 3 Simulation results of the average wind profile

After the wind field flowed $12 \mathrm{~m}$ and $24 \mathrm{~m}$, the fluctuating wind power spectrums and the coherence function can be simulated according to the speed of the monitoring points at the height of $1 \mathrm{~m}$ and $2 \mathrm{~m}$. The power spectrums were compared with the theoretical value, as shown in Figs. 5 and 6. And the coherence functions were compared with the target value, as shown in Figs. 7 and 8. It can be seen from Figs. 5 and 6 that the numerical simulation of the wind speed spectrum and the theoretical power spectrum are in good agreement between $0.1-1 \mathrm{~Hz}$, and the simulation result at $24 \mathrm{~m}$ from the inlet is closer to the theoretical value. Although the wind speed spectrum of the numerical simulation results is slightly smaller than the theoretical power spectrum, it has met the requirements of long-span bridge design.

It can be seen from Figs. 7 and 8 that the autocorrelation and cross-correlation at $24 \mathrm{~m}$ from the inlet are also closer to the target value than those at $12 \mathrm{~m}$ because of a longer 


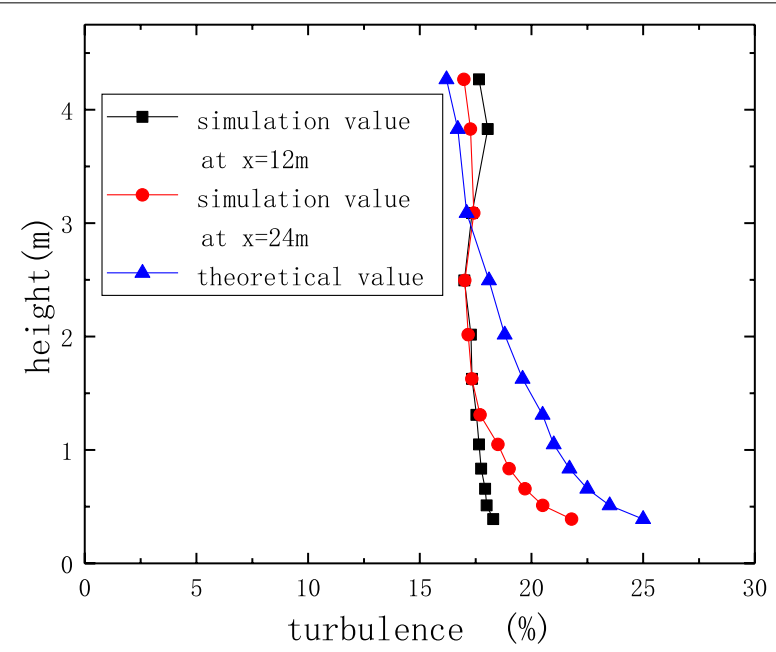

Fig. 4 Simulation results of the turbulence intensity

distance flow. Therefore, this fluctuating wind simulation method is a good way to simulate the wind speed spectrum and correlation of the fluctuating wind.

\subsubsection{Comparison of different turbulence models}

Besides, to verify the accuracy of the LES method and the RANS method (SST k-w model) in the simulation of the fluctuating wind, both methods were used to simulate

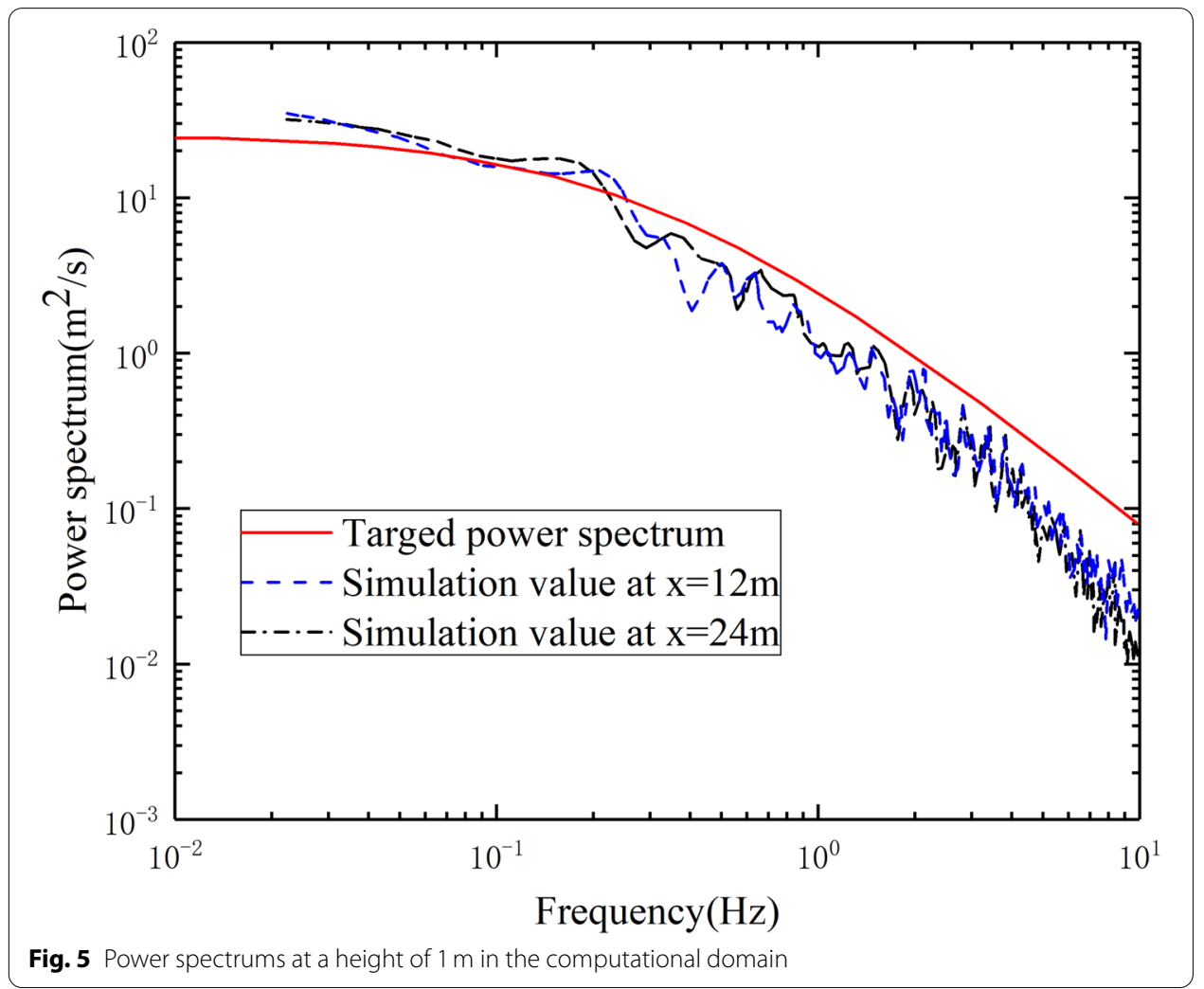




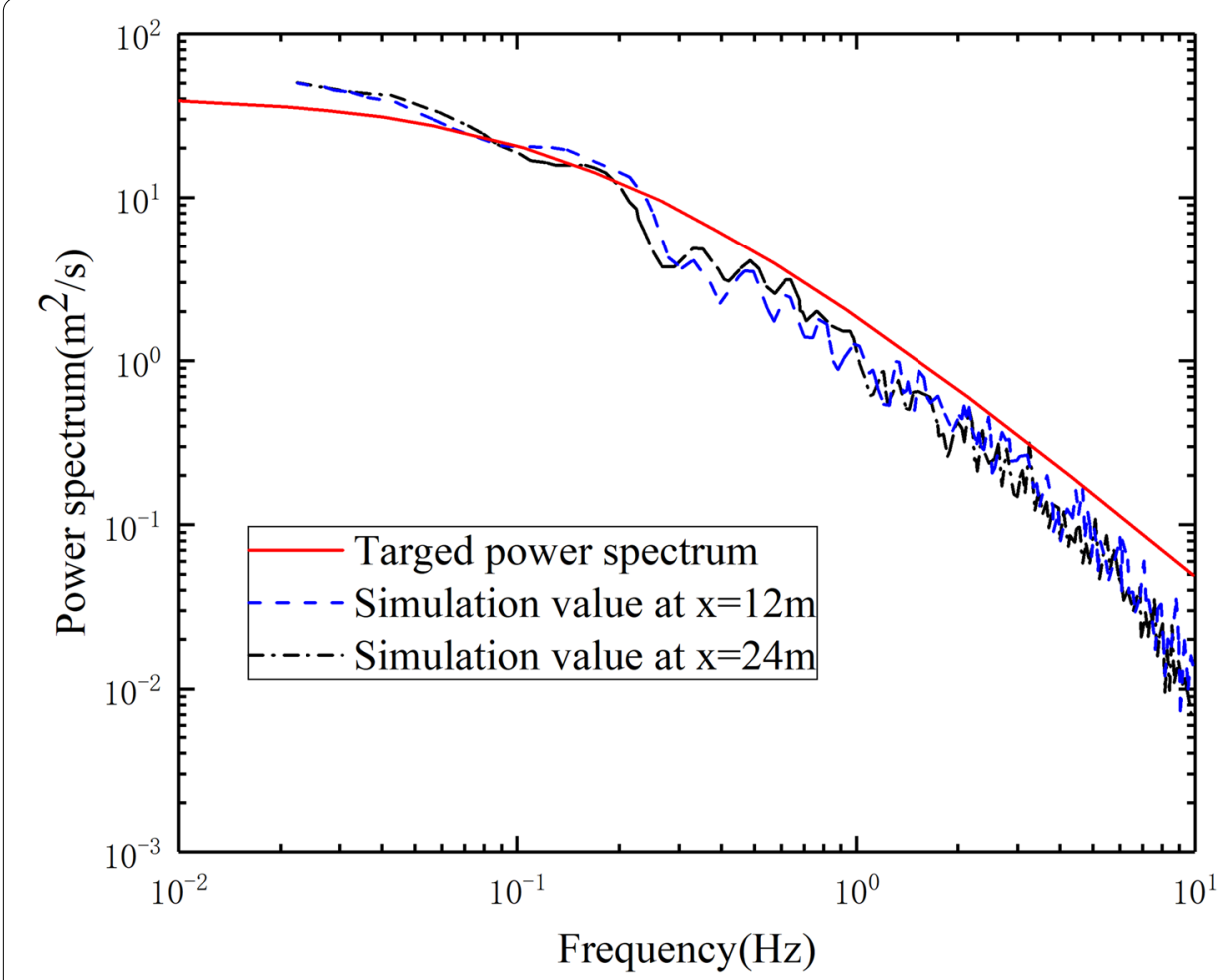

Fig. 6 Power spectrums at a height of $2 m$ in the computational domain

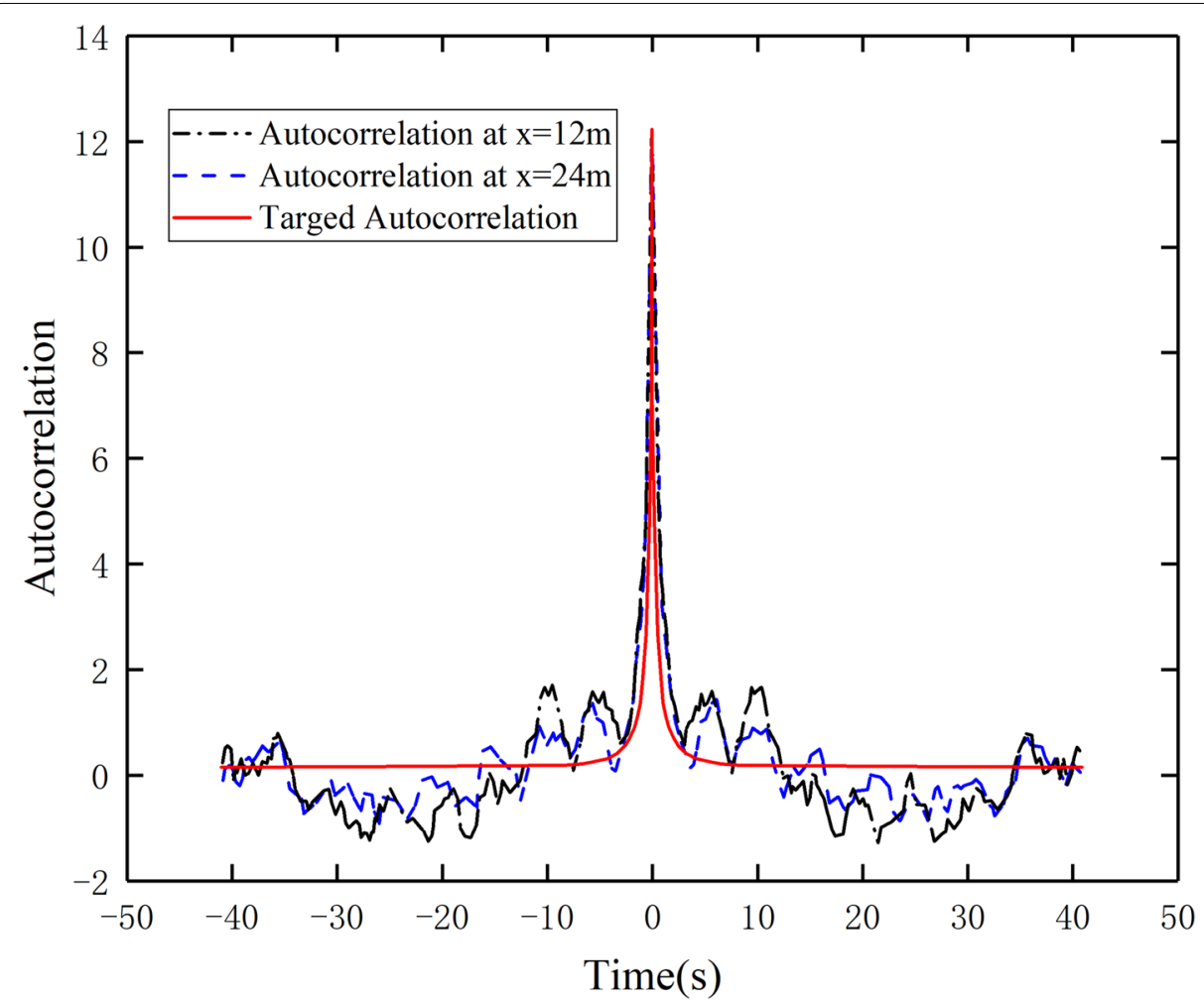

Fig. 7 Autocorrelation functions at a height of $1 \mathrm{~m}$ in the computational domain 


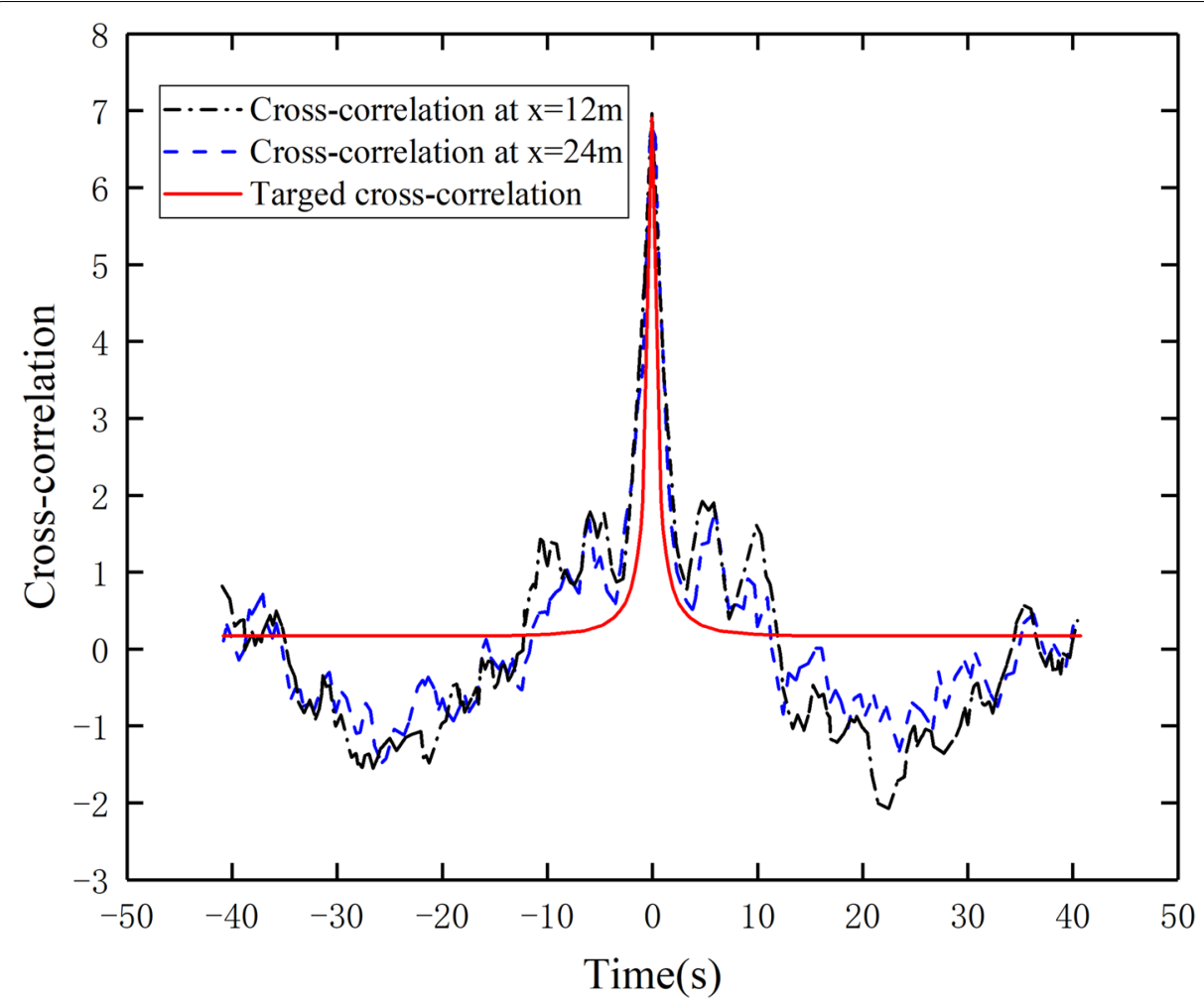

Fig. 8 Cross-correlation functions at a height of $1 \mathrm{~m}$ and $2 \mathrm{~m}$ in the computational domain

the turbulence intensity profile at $24 \mathrm{~m}$ from the inlet and the results were compared, as shown in Fig. 9. It can be seen that the turbulence intensity profile simulated by the large eddy simulation (LES method) is closer to the theoretical result, so the LES method is more accurate for the fluctuating wind field simulation than RANS method.

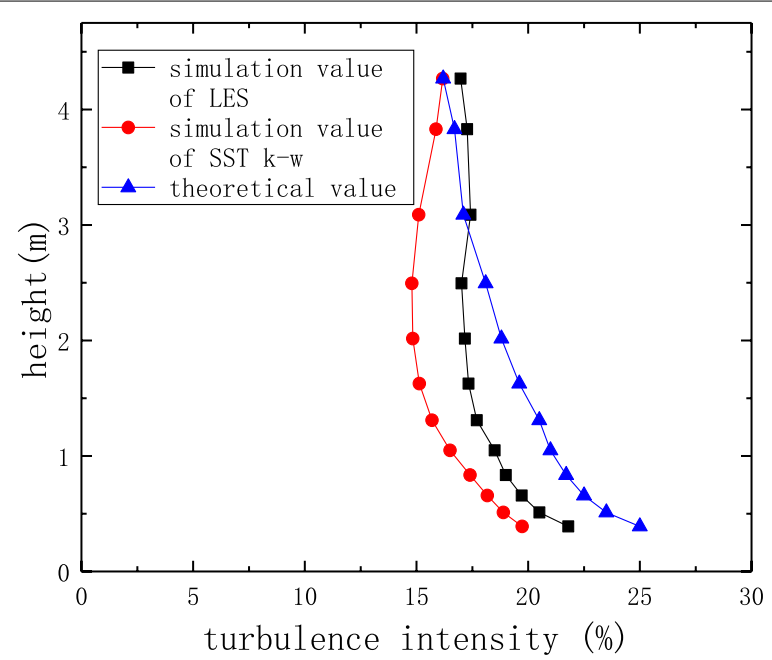

Fig. 9 Turbulence intensity profiles of turbulence model 


\section{Numerical analysis model of bridge site in mountainous area}

\subsection{Computational model}

Taking a bridge in a mountainous area in Yunnan as the engineering background, the computational domain size is set to $8 \mathrm{~km} \times 6 \mathrm{~km} \times 5 \mathrm{~km}$ (length $\times$ width $\times$ height). The terrain was set as smooth wall boundaries, and the bridge site is located at the center of the computational domain. The three-dimensional numerical model of the terrain at the bridge site is shown in Fig. 10. The mesh near the terrain surface is densely divided to ensure calculation accuracy. The model is discretized by a quadrilateral unstructured gird of which the total number is 3.1 million. The grid height of the first layer is $2 \mathrm{~m}$, and the upward growth rate is 1.1. The overall and partial mesh is shown in Fig. 11.

\subsection{Computational parameter setting}

According to the study in Section 2, the large eddy simulation is more accurate in fluctuating wind simulation, so the turbulence model used to simulate the fluctuating wind field is the LES (large eddy simulation) of the Smagorinsky subgrid-scale model. The discretized problem is numerically solved by using a SIMPLE pressure-velocity coupling algorithm.

The inlet boundary condition of the mean wind flow adopted the average wind velocity profile, which is compiled by UDF (user-defined function). The altitude of the wind gradient is taken as $1000 \mathrm{~m}$ (average altitude of regional terrain $(550 \mathrm{~m})+$ height of boundary layer of terrain surface type D). According to the local weather station, the gradient wind speed in the area is $43.6 \mathrm{~m} / \mathrm{s}$. The velocity is assumed to be $43.6 \mathrm{~m} / \mathrm{s}$ when the altitude is greater than $1000 \mathrm{~m}$, and the velocity varies according to the altitude by an exponential law when the altitude is below $1000 \mathrm{~m}$. The formula for the inlet velocities is given by eq. (1), and the wind velocity distribution is shown in Fig. 12. The inlet wind velocity at the bridge deck is set to $30.27 \mathrm{~m} / \mathrm{s}$.

The inlet boundary condition of the fluctuating wind flow adopts the input method of the fluctuating wind in Section 2. The fluctuating wind is simulated by the weighted amplitude wave superposition (WAWS) method, and the Simiu spectrum is used for the power spectrum of the fluctuating wind in the downwind direction.

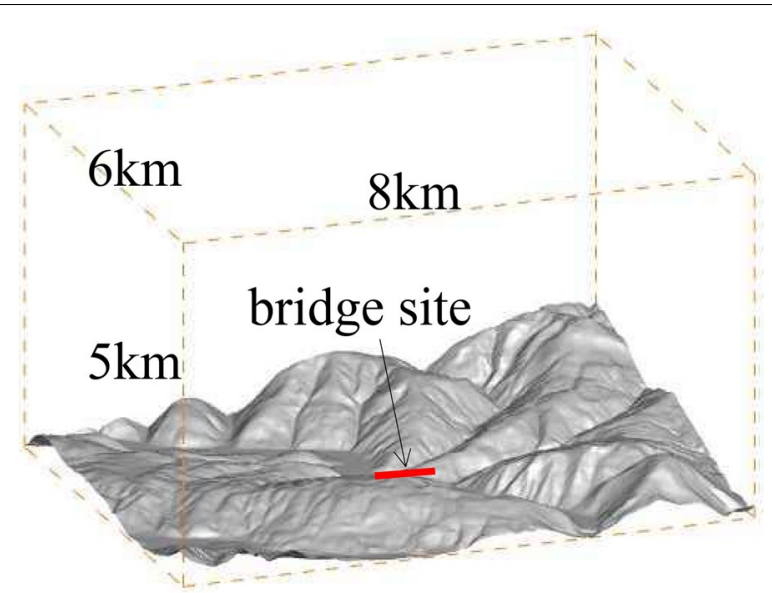

Fig. 10 Numerical model of the terrain at the bridge site 


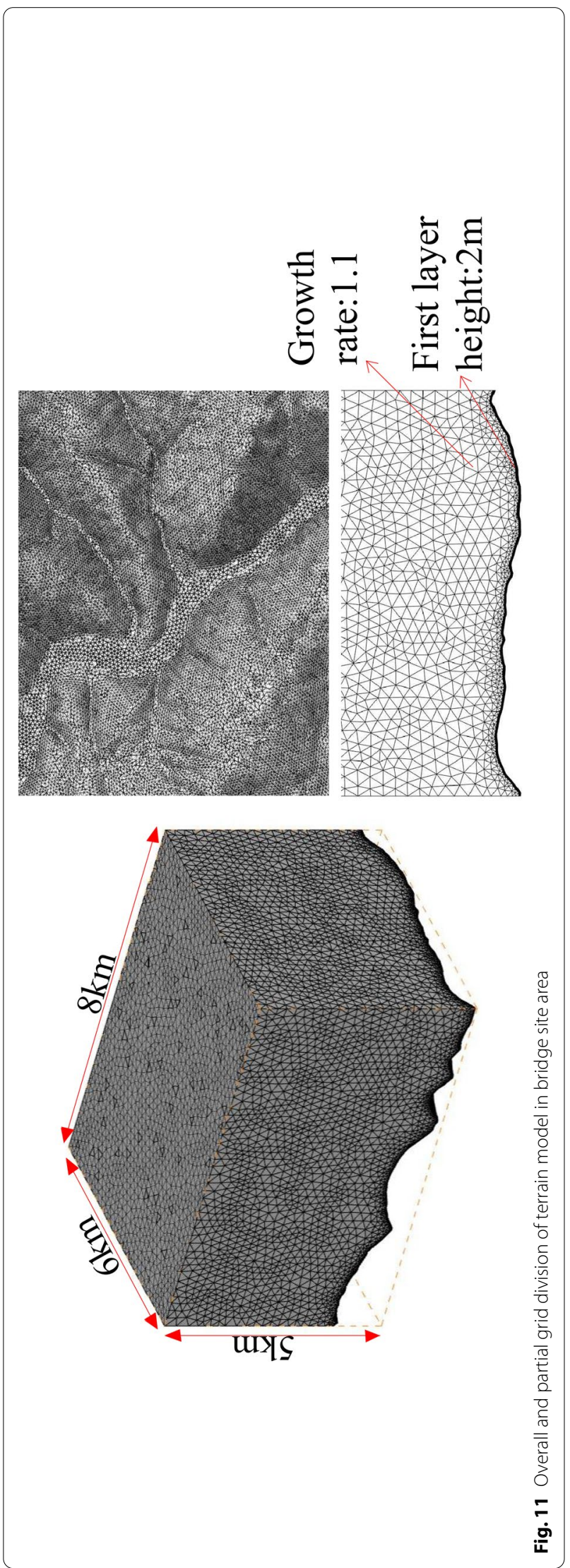




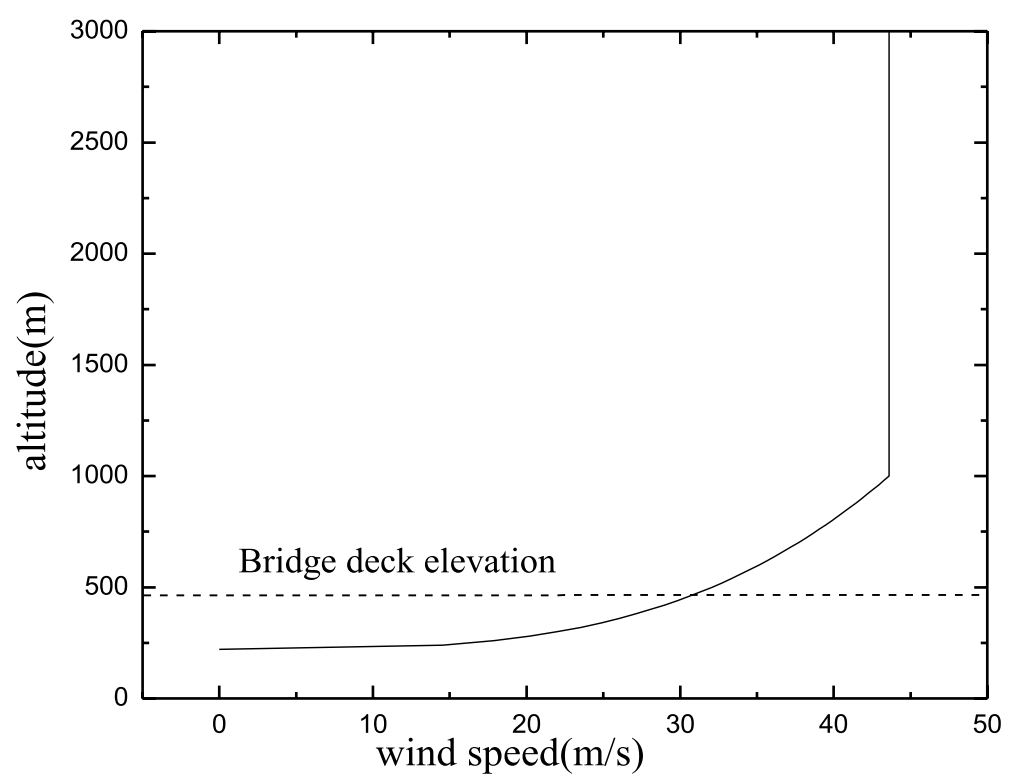

Fig. 12 Wind velocity distribution

$$
\begin{aligned}
& H(\text { elevation })>1000 \mathrm{~m}: \quad V=43.6 \mathrm{~m} / \mathrm{s} \\
& 1000 \geq H \geq 220 \mathrm{~m}: \quad V=43.6 \times\left(\frac{H-220}{780}\right)^{0.30} \mathrm{~m} / \mathrm{s}
\end{aligned}
$$

\subsection{Working condition setting}

Due to the influence of the terrain, the wind environment of the bridge site is very different under different wind flow directions. In this study, six different wind flow directions were selected according to the main bending directions of the river at the bridge site. Starting from the direction of $83.7^{\circ}$ west-south, there is one working condition every $20^{\circ}$. The working conditions of the mean wind flow were case 1 to 6 , and the working conditions of the fluctuating wind flow were case 7 to 12 . The working conditions under the fluctuating wind and the mean wind are in one-to-one correspondence (shown in Fig. 13).

To obtain the wind environment parameters at different positions of the main beam, one monitoring point is arranged for every $1 / 8$ of the length of the main beam. To obtain the vertical characteristics of the wind speed change in the bridge site area, observation points are arranged in the vertical direction at the $1 / 4$ span, $1 / 2 \mathrm{span}$, and 3/4 span of the main beam. The spatial distribution of each monitoring point is shown in Fig. 14.

\section{Result analysis}

\subsection{Average wind characteristic}

\subsubsection{Wind profile}

The average wind profile at the mid-span of the bridge under the mean wind flow condition and the fluctuating wind flow condition is shown in Fig. 15. The average wind speed profile of the bridge under the two wind flow conditions is basically the same. Overall, when the direction of wind flow is similar to the river, the wind profile of the bridge is 


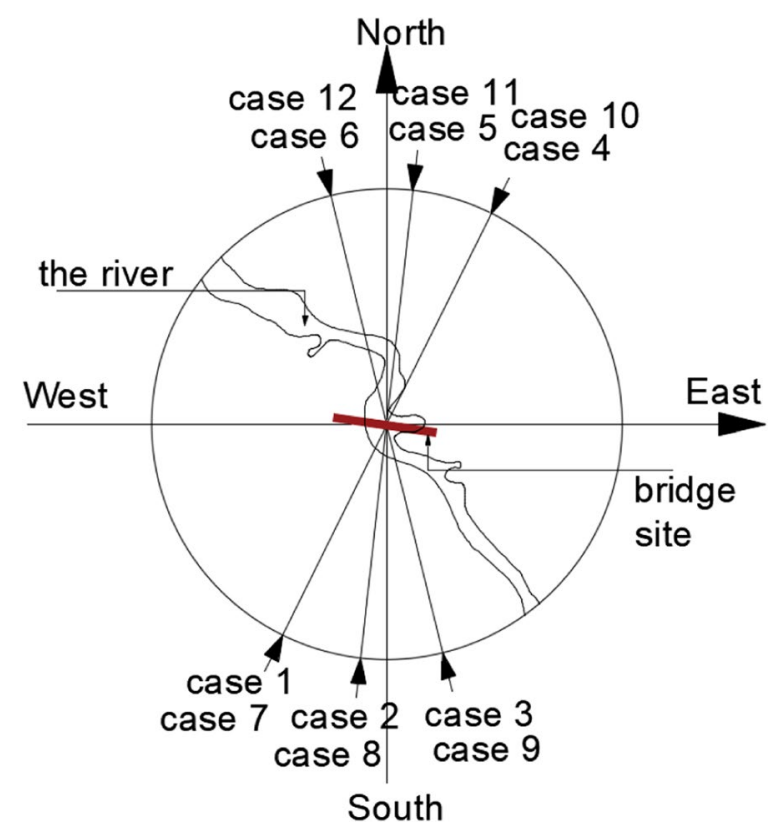

Fig. 13 Working condition

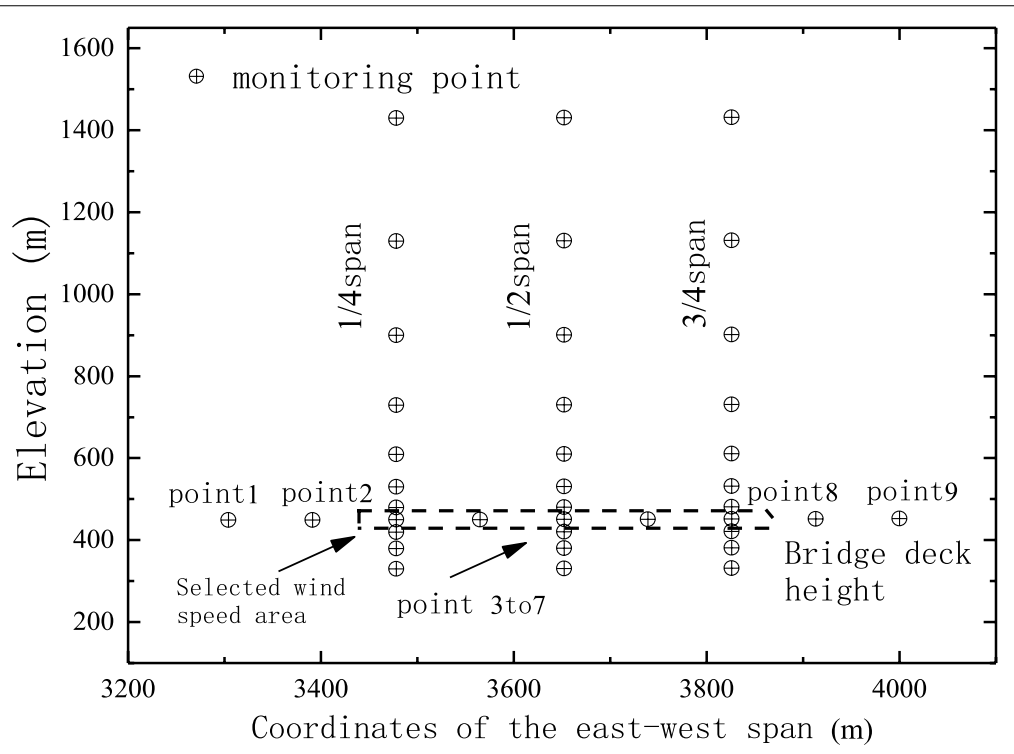

Fig. 14 Distribution of monitoring points

closer to the exponential distribution because the average wind characteristic is affected by the average wind speed at the inlet boundary and the terrain rather than the pulsating component of the wind.

\subsubsection{Wind attack angle and wind direction angle}

The wind attack angle and wind direction angle of the measurement points at the bridge deck under the two wind flow conditions are compared. The distribution of the wind direction angle along the main beam is shown in Fig. 16, and the 


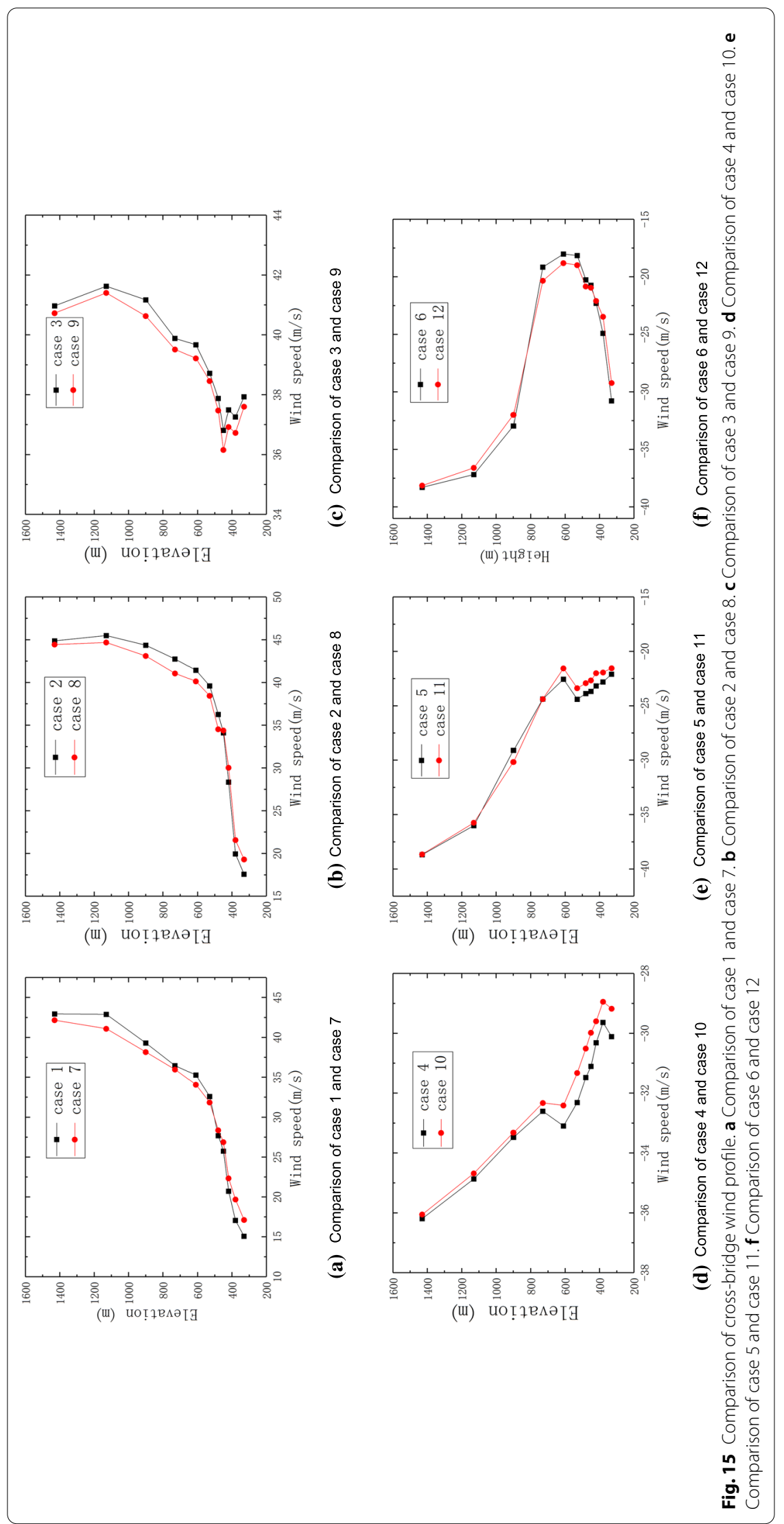




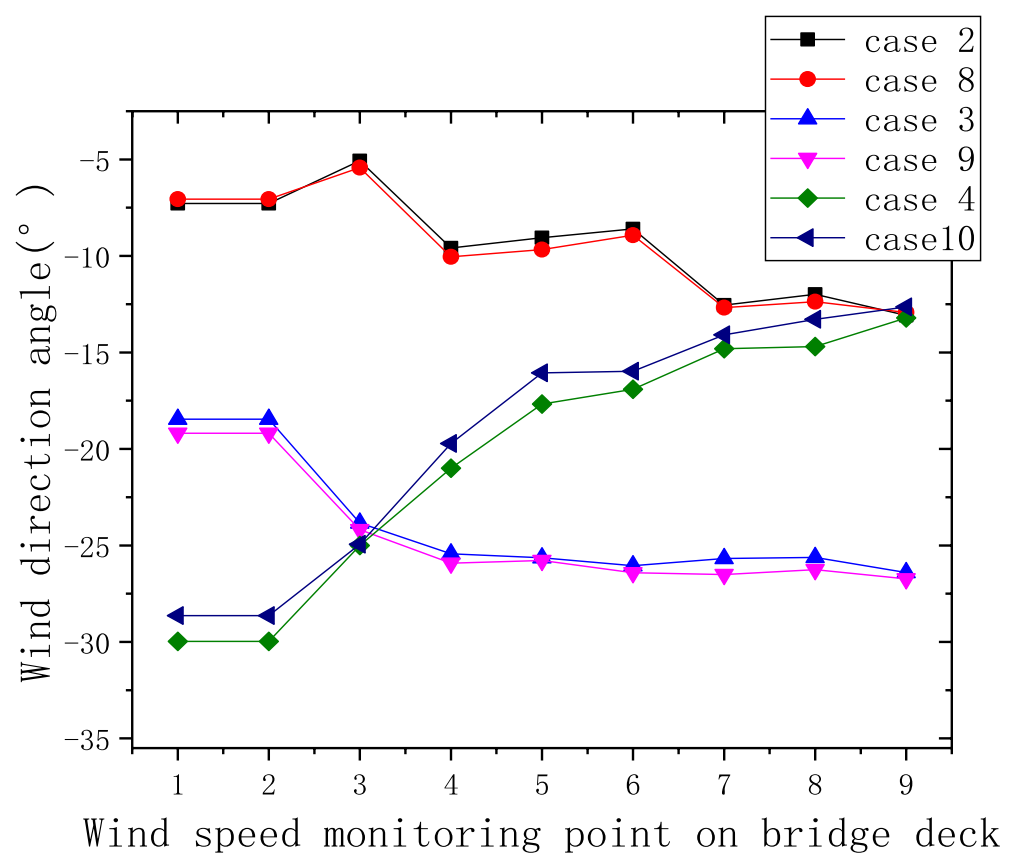

Fig. 16 Comparison of wind direction angle

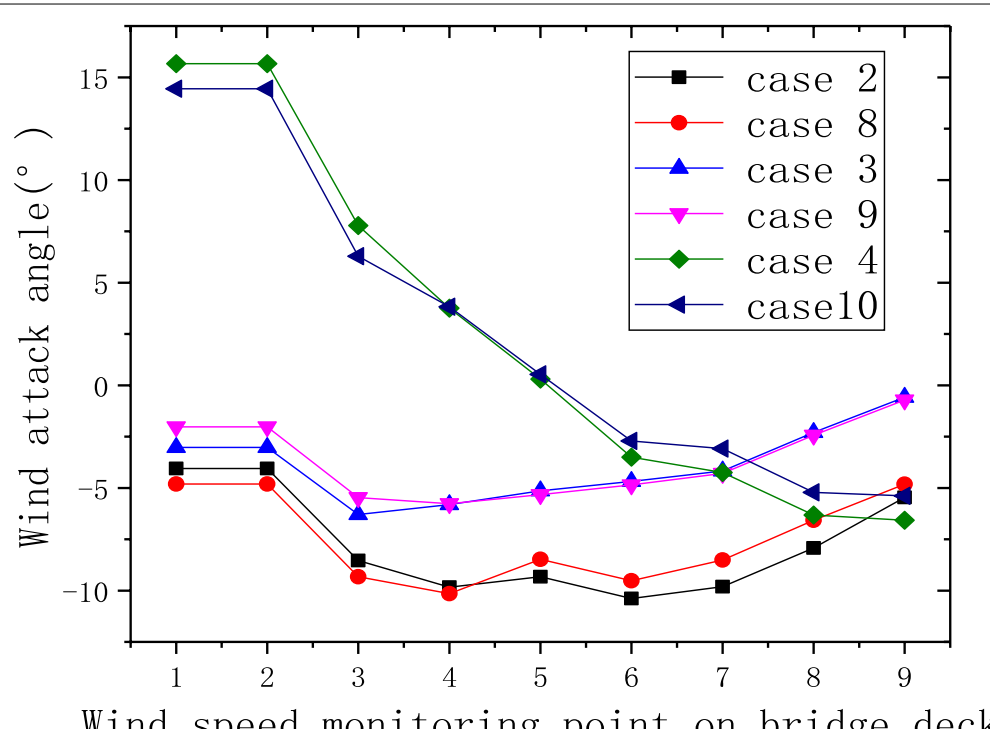

Fig. 17 Comparison of wind attack angle

distribution of the wind attack angle along the main beam is shown in Fig. 17. The distribution of the wind direction angle and the wind attack angle of the fluctuating wind flow is basically the same as that of the mean wind flow, which shows that the fluctuating wind flow has a limited impact on the wind direction angle and the wind attack angle. 


\subsubsection{Bridge deck wind speed}

The comparison of the wind speed of the bridge deck under the two wind flow conditions is shown in Tables 1 and 2. It can be seen from the tables that the wind speed across the bridge at the height of the bridge deck and the wind speed along the bridge are basically the same under the two wind flow conditions, which shows that the influence of the fluctuating wind flow on the average wind characteristics of the bridge site area can be ignored.

\subsection{Fluctuating wind characteristic}

\subsubsection{Wind speed time history comparison}

To understand the fluctuating wind characteristic at the bridge site under different wind flow boundary conditions, the mid-span bridge deck wind speed time history of case 2, 3, 5, and 6 (mean wind working conditions) and case 8, 9, 11, and 12 (fluctuating wind working conditions) were compared one by one. The comparison results are shown in Fig. 18.

Notably, because the wind flow direction of case 9 and case 3 is basically the same as the direction of the river, the terrain pulsation effect is small. In addition, the mean flow has no fluctuation components, so in these two cases, the wind speed history has almost no fluctuation; seen in Fig. 18 (b). But when the mean wind flow does not follow the direction of the river, terrain pulsation effect will have an impact on wind speed fluctuation. So, in other cases, the fluctuation of wind speed time history under mean wind flow is larger than that of case 3 and case 9.

By comparing, it is clear that the wind speed fluctuation under the mean wind flow is relatively large, but smaller than the wind speed fluctuation under the fluctuating wind. So, it is found that LES method is able to reflect the pulsation characteristics of turbulent flow well and the fluctuating wind characteristics are mainly affected by the terrain and the pulsating component of the wind flow.

\subsubsection{Turbulence intensity}

The cross-bridge turbulence profiles of different working conditions under the mean wind flow and the fluctuating wind are shown in Fig. 19. It can be seen from the figures that the terrain will still produces a certain pulsation effect under the mean wind flow when the wind flow and the river have a certain angle within the influence range of the terrain. Comparing the simulation results of the fluctuating wind flow condition, the turbulence intensity under the fluctuating wind flow is larger because the turbulence intensity at the bridge site is affected by the terrain pulsating effect and the pulsating component of the fluctuating wind. Therefore, the turbulence under the average wind should be smaller than that under the fluctuating wind. In case 3 , the wind flow direction is basically the same as the direction of the river at the bridge site, and the terrain pulsation effect is very weak, so the turbulence intensity at the bridge site under the mean wind flow is close to 0 . The turbulence intensity of the fluctuating wind flow along the river is only affected by the pulsating component of the fluctuating wind. Therefore, the wind environment numerical simulation in the complex 


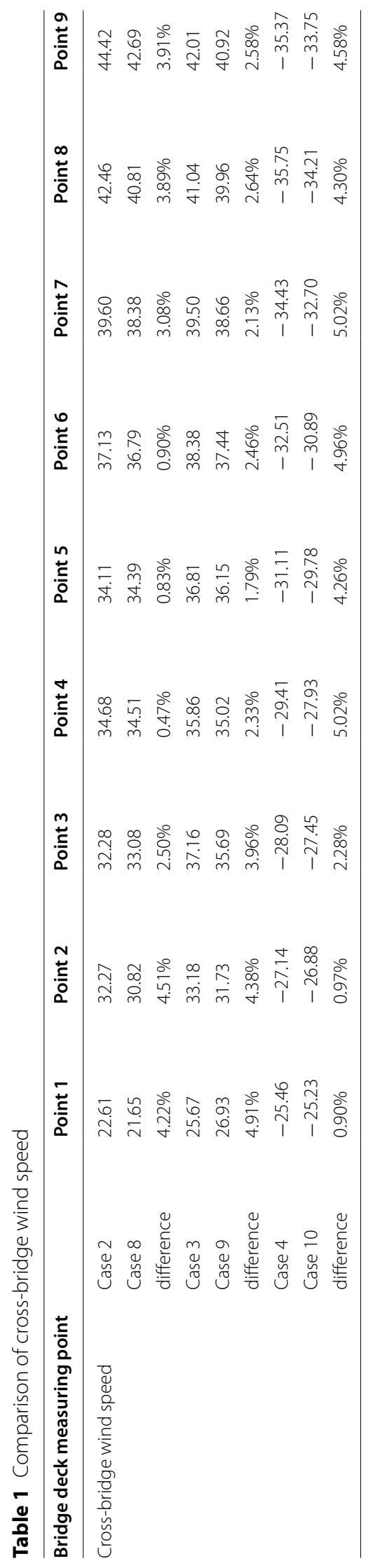




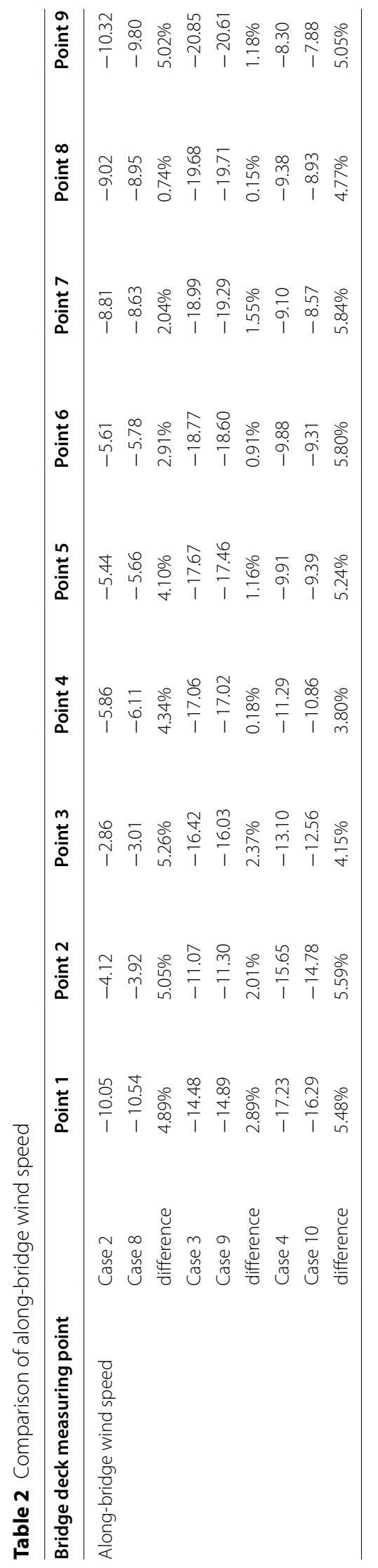




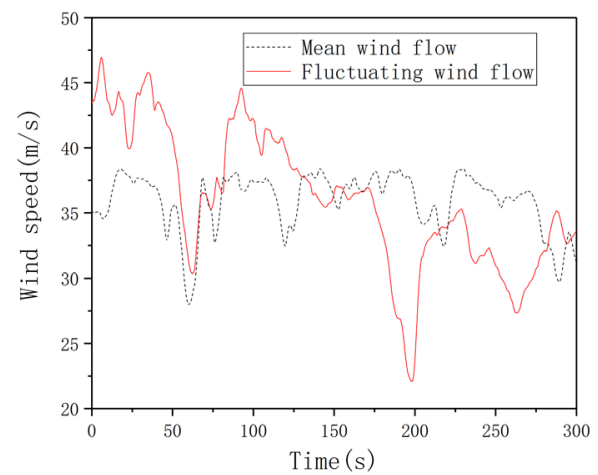

(a) Comparison of case 2 and case 8

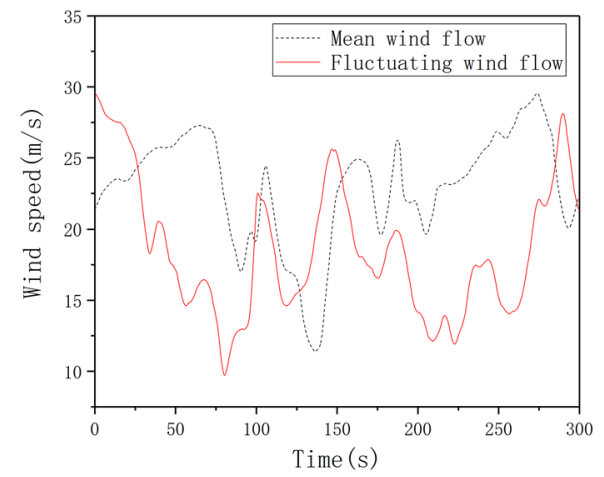

(c) Comparison of case 5 and case 11

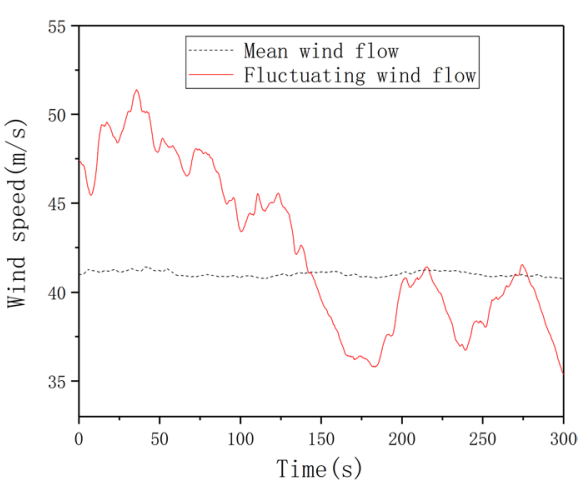

(b) Comparison of case 3 and case 9

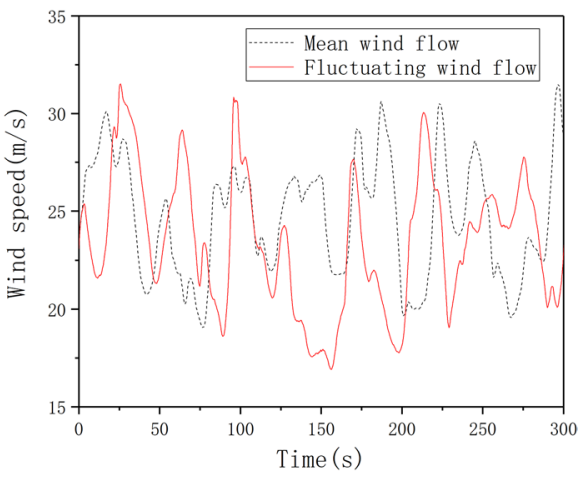

(d) Comparison of case 6 and case 12

Fig. 18 Wind speed time history under different wind flow. a Comparison of case 2 and case 8 . $\mathbf{b}$

Comparison of case 3 and case 9. c Comparison of case 5 and case 11. $\mathbf{d}$ Comparison of case 6 and case 12

mountainous terrain should not only consider the pulsating effect of the terrain, but also fully consider the pulsating component of the wind flow. Otherwise, the fluctuating wind characteristics at the bridge site will be inconsistent with the actual situation when there is an angle between the wind flow and the river course.

To study the relative magnitude of the pulsation effect caused by the terrain and the pulsating component of the wind flow, the Cross-bridge turbulence intensity of the nine measuring points that distribute in the middle span, 1/4 span, 3/4 span near the bridge deck were compared to get the turbulence ratio between the mean wind and the fluctuating wind, as shown in Table 3. It can be seen from the table that the pulsation effects caused by terrain are different in different wind flow directions.

In the $3 / 4$ span of case 8 , the terrain along the wind flow is relatively flat and the terrain pulsation effect is weak. As a result, the turbulence ratio is small. When the angle between the wind direction and the river direction is relatively big and the terrain is relatively steep, the turbulence ratios of the measuring points near the bridge deck under the mean wind and the fluctuating wind are all above 0.95 , which shows that the pulsation effect in this situation is mainly caused by the terrain. But when the direction of the wind flow is along the river, the turbulence ratios at the bridge site are basically below 0.1 , which indicates that the pulsation effect in this situation is mainly caused by the pulsating component of the wind flow rather than the terrain. So, the numerical simulation of 


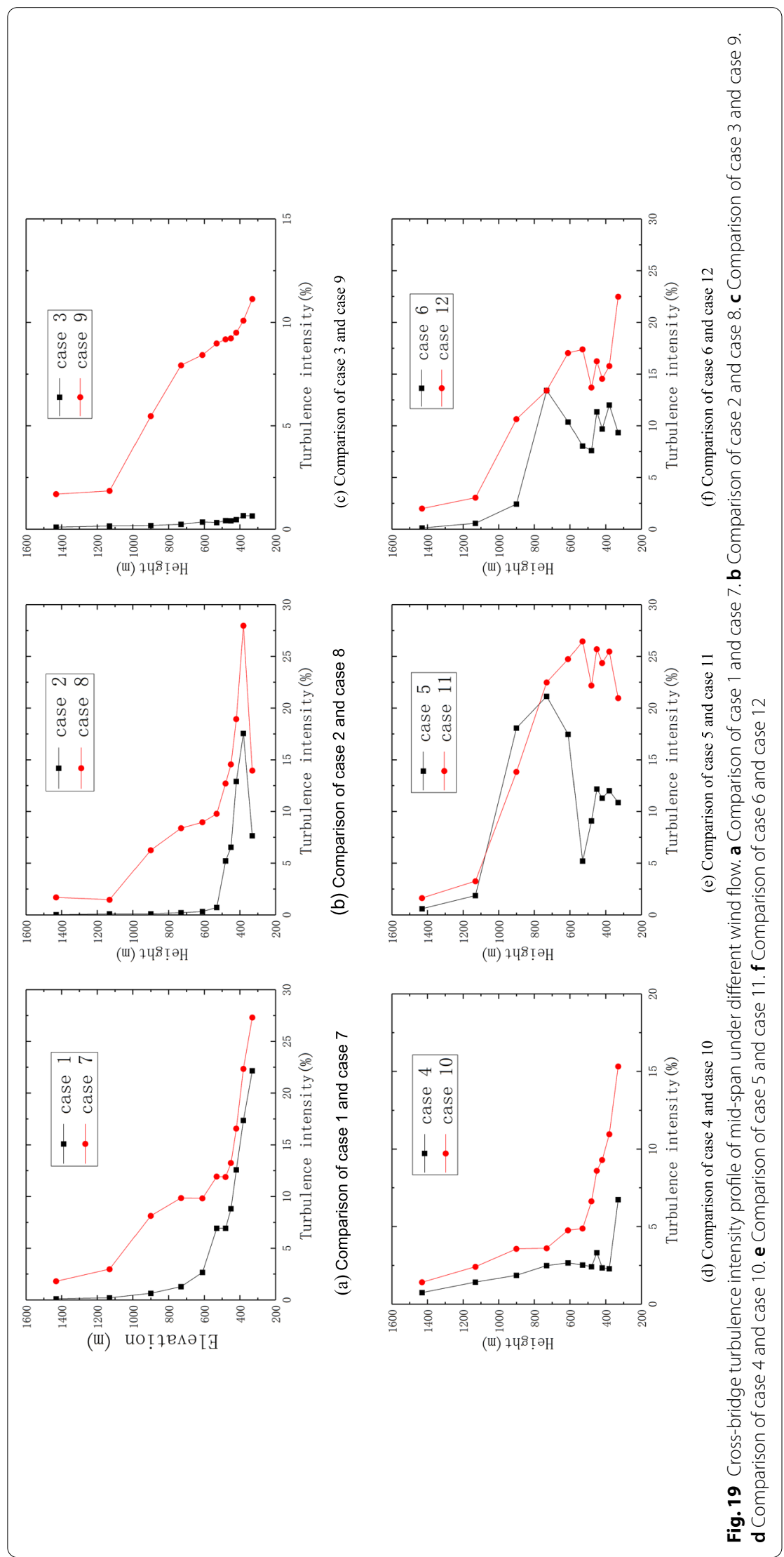


Table 3 Turbulence ratio under different working conditions

\begin{tabular}{|c|c|c|c|c|c|c|c|}
\hline \multicolumn{2}{|c|}{ Working condition } & \multirow{2}{*}{$\begin{array}{l}\text { Case } \\
\mathbf{7} 、 1 \\
0.97\end{array}$} & \multirow{2}{*}{$\begin{array}{l}\text { Case } \\
\mathbf{8} \cdot \mathbf{2} \\
0.26\end{array}$} & \multirow{2}{*}{$\begin{array}{l}\text { Case } \\
\mathbf{9} \cdot \mathbf{3} \\
0.07\end{array}$} & \multirow{2}{*}{$\begin{array}{l}\text { Case } \\
10 、 4\end{array}$} & \multirow{2}{*}{$\begin{array}{l}\text { Case } \\
\mathbf{1 1} \cdot \mathbf{5}\end{array}$} & \multirow{2}{*}{$\begin{array}{l}\begin{array}{l}\text { Case } \\
12 \cdot 6\end{array} \\
0.54\end{array}$} \\
\hline $1 / 4$ span & Above bridge & & & & & & \\
\hline & On bridge deck & 0.94 & 0.43 & 0.05 & 0.98 & 0.33 & 0.61 \\
\hline & Under bridge & 0.96 & 0.91 & 0.11 & 0.99 & 0.34 & 0.62 \\
\hline \multirow[t]{3}{*}{ Mid-span } & Above bridge & 0.58 & 0.41 & 0.05 & 0.36 & 0.41 & 0.55 \\
\hline & On bridge deck & 0.67 & 0.45 & 0.04 & 0.39 & 0.47 & 0.70 \\
\hline & Under bridge & 0.76 & 0.68 & 0.05 & 0.25 & 0.46 & 0.67 \\
\hline \multirow[t]{3}{*}{ 3/4span } & Above bridge & 0.82 & 0.06 & 0.09 & 0.22 & 0.71 & 0.40 \\
\hline & On bridge deck & 0.83 & 0.16 & 0.08 & 0.16 & 0.75 & 0.58 \\
\hline & Under bridge & 0.84 & 0.09 & 0.09 & 0.23 & 0.68 & 0.47 \\
\hline
\end{tabular}

the wind environment should consider the fluctuating wind condition to ensure that the numerical simulation results are safer and more accurate.

\subsubsection{Power spectrum}

The cross-bridge fluctuating wind speed time history at the mid-span measurement point of the main girder was analyzed to obtain the fluctuating wind power spectrum at the mid-span measurement point of the main girder. Comparing the power spectrum of the numerical simulation with the Simiu spectrum and the Von Karman spectrum, the result is shown in Fig. 20.

It can be seen from the figure that the cross-bridge fluctuating wind power spectrum of the numerical simulation in various working conditions is basically consistent with the Von Karman spectrum in the low frequency range (shown in Eq. 2). But when the frequency is greater than 0.1 , the simulated power spectrum is quite different from the theoretical spectrum.

Currently, the high-frequency attenuation phenomenon is common in the simulated wind power spectrum. $\mathrm{s}$ is because the high frequency band represents the energy contribution of the small-scale vortices in the wind field, and the small-scale vortices cannot be solved directly in the LES method, so the numerical simulation cannot capture the high frequency wind spectrum of the fluctuating wind field. This problem can be improved by improving the turbulence model and the number of dense grids.

$$
\frac{n S(z, n)}{\sigma_{u}^{2}}=\frac{4\left(n L_{u}^{x} / U\right)}{\left[1+70.8\left(\frac{n L_{u}^{x}}{U}\right)^{2}\right]^{5 / 6}}
$$

Note: $\sigma_{u}$ is the root mean square value of pulsating wind, and $L_{u}^{x}$ is the integral scale of turbulence in the downwind direction.

\section{Conclusion}

In this paper, a numerical simulation study of the complex wind environment in the western mountainous area was carried out. First, the correctness of the numerical simulation of the fluctuating wind field was verified in the numerical empty wind tunnel, and then taking the 


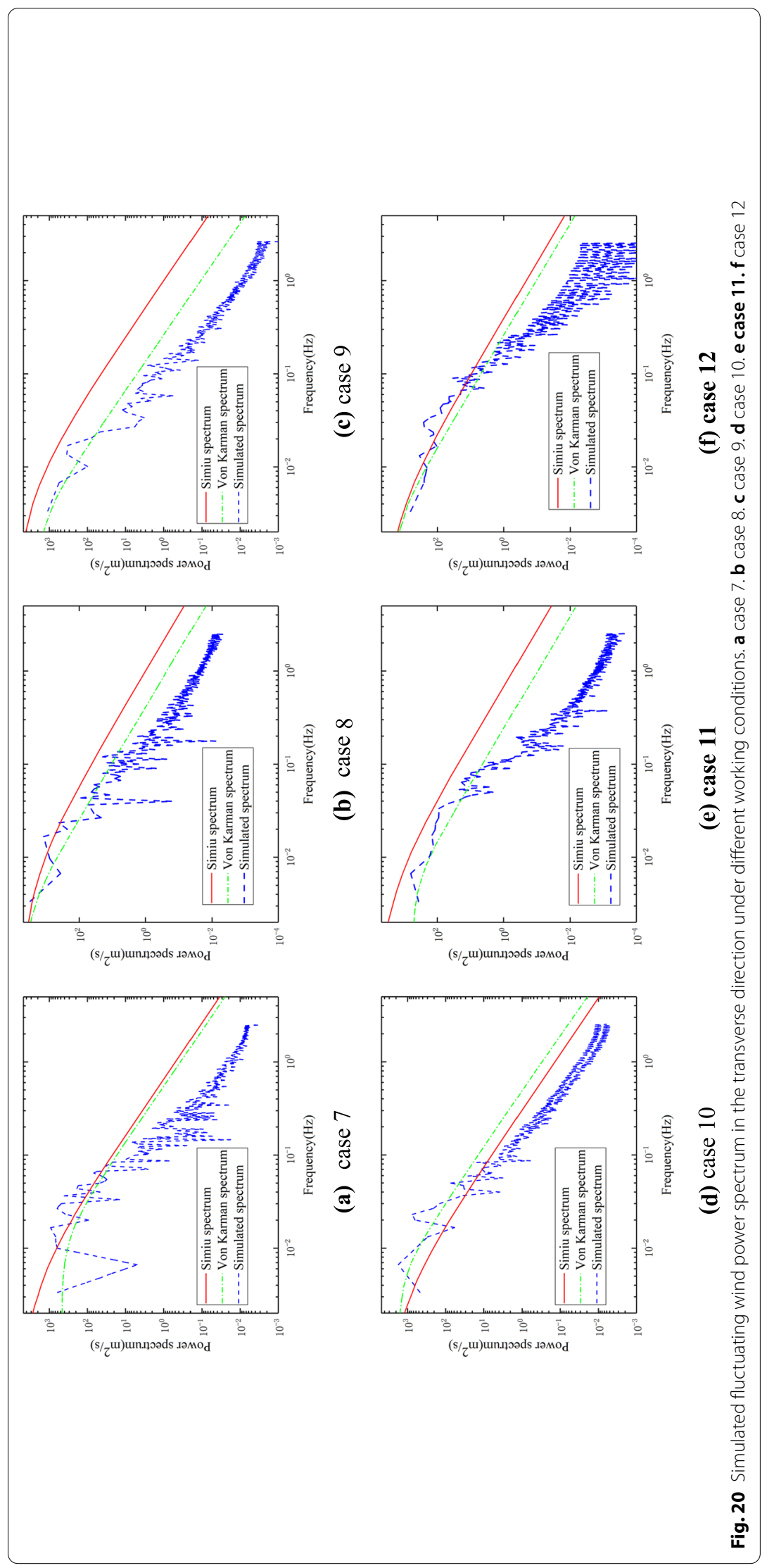


terrain of a bridge site in Yunnan as the research object, the numerical simulation research work was carried out under the mean wind flow and the fluctuating wind flow, and the average wind characteristics and fluctuating wind characteristics at the bridge site under the two boundary conditions were discussed and compared. Get the following conclusions:

(1) Through the simulation of the empty wind tunnel, the feasibility of the large eddy simulation method (LES) based on WAWS to simulated the fluctuating wind is verified. Compared with the Reynolds average method, the LES method simulated the fluctuating wind better. And the turbulence characteristics of the fluctuating wind that simulated by this method is more accurate than using the SST k-w model.

(2) The average wind characteristics such as the across-bridge wind profile, the wind attack angle, the wind direction angle, and the bridge deck wind speed under the mean wind flow and the fluctuating wind flow are not much different, which indicates that both the Reynolds average method and the LES method can simulate the average wind field characteristics well.

(3) The fluctuating wind characteristic at the bridge site is mainly affected by the terrain and the pulsating component of the wind flow. Therefore, the wind environment numerical simulation in the complex mountainous terrain should not only consider the pulsating effect of the terrain, but also fully consider the pulsating component of the wind flow, especially when there is an angle between the wind flow and the river course. In addition, it is a characteristic of the fluctuating wind simulation method that the simulated power spectrum coincides with the Von Karman spectrum relatively well.

(4) When the angle between the wind flow and the river is relatively big and the terrain is relatively steep, the turbulence intensity under the mean wind and the fluctuating wind is similar. But when the wind flow is along the river, the turbulence intensity is much different, which indicates that the pulsation effect in this situation is mainly caused by the pulsating component of the wind flow rather than the terrain. So, the numerical simulation of the wind environment should consider the fluctuating wind to ensure the numerical simulation results more accurate.

There are some shortcomings in this research that need further improvement and research. Subjected by the calculation conditions, the number of computational domain grids is limited, which also leads to a large attenuation of the numerically simulated wind power spectrum in the high frequency range. In future research, to obtain more ideal simulation results, the number of grids must be increased and computing resources should be more reasonably used.

\section{Abbreviations}

WAWS: Weighted Amplitude Wave Superposition; LES: Large Eddy Simulation; CFD: Computational Fluid Dynamics; UDF: User-defined Function; WRF: Weather Research and Forecast.

\section{Acknowledgements}

Not applicable.

\section{Authors'contributions}

Longfei Xing:Writing, Data Curation, Formal analysis. Mingjin Zhang: Investigation, Writing-Original Draft and Visualization. Yongle Li: Term, Resources, Funding acquisition and Supervision. Zhijie Zhang: Conceptualization, Methodology, Writing - Review \& Editing and Supervision. Dianguo Yin: Review \& Editing and Supervision, the authors read and approved the final manuscript. 


\section{Funding}

The work described in this paper was fully supported by a grant from the National Key Research and Development Program of China (No. 2018YFC1507800).

Availability of data and materials

The data generated or analyzed during this study are included in this published article.

\section{Declarations}

\section{Competing interests}

The authors declare that they have no known competing financial interests or personal relationships that could have appeared to influence the work reported in this paper.

Author Yongle Li is Editor-in-Chief of Advances in Bridge Engineering.

\section{Author details}

${ }^{1}$ Department of Bridge Engineering, Southwest Jiaotong University, 610031 Chengdu, Sichuan, PR China. ${ }^{2}$ Yunna Transportation Planning and Design Institute Co., Ltd., 650041 Kunming, Yunnan, PR China. ${ }^{3}$ Chongqing University Architectural Planning and Design Research Institute Co., Ltd., 610031 Chongqing, PR China.

Received: 31 May 2021 Accepted: 13 September 2021

Published online: 05 October 2021

\section{References}

Aider JL, Danet A (2006) Large-eddy simulation study of upstream boundary conditions influence upon a backwardfacing step flow. Comptes Rendus Mécanique 334(7):447-453

Cao S, Wang T, Ge Y, Tamura Y (2012) Numerical study on turbulent boundary layers over two-dimensional hills — effects of surface roughness and slope. J Wind Eng Ind Aerodynamics 104:342-349

Davenport AG (1987) The spectrum of horizontal gustiness near the ground in high winds. Q J R Meteorol Soc 87(372):194-211

lizuka S, Kondo H (2004) Performance of various sub-grid scale models in large-eddy simulations of turbulent flow over complex terrain. Atmos Environ 38:7083-7091

Kataoka H (2008) Numerical simulations of a wind-induced vibrating square cylinder within turbulent boundary layer. J Wind Eng Ind Aerodyn 96(10-11):1985-1997

Li QS, Fang JQ, Jeary AP et al (1998) Full scale measurements of wind effects on tall buildings. J Wind Eng Ind Aerodynamics $74: 741-750$

Li Y, Peng H, Xu X (2017) Wind characteristics at bridge site in a deep-cutting gorge by wind tunnel test. Qiu, J, JWind Eng Ind Aerodynamics 160

Li Y, Zhang M, Xing X et al (2014) Causes of daily strong wind on bridge site in deep gorge with high altitude and high temperature difference. J Southwest Jiaotong Univ 49(06):935-941

Liu Z, Chen X, Chen Z (2019) Optimization of transition sections around terrain model at mountain canyon bridge site. J China Highway 32(10):266-278

Maurizi A, Palma JMLM, Castro FA (1998) Numerical simulation of the atmospheric flow in a mountainous region of the north of Portugal. J Wind Eng Ind Aerodynamics 74(6):219-228

Shen L, Han Y, Cai C, Dong G (2015) Research on generating method of fluctuating wind field of LES based on WAWS. J Hunan Univ 42(11):64-71

Shen L, Han Y, Cai C et al (2016) Experiment and numerical simulation for wind field of a long-span suspension bridge located in mountainous canyon. J Hunan Univ 43(7):16-24

Shen L, Han Y, Dong G et al (2017) Numerical simulation of wind field on bridge site located in mountainous area and gorge based on WRF. China J Highway Transport 30(5):104-114

Shen L, Hua X, Han Y et al (2020) Numerical simulation of wind field at canyon bridges with high precision inlet boundary. China J Highway Transport 33(7):114-123

Tamura T, Okuno A, Sugio Y (2000) LES analysis of turbulent boundary layer over 3D steep hill covered with vegetation. J Wind Eng Ind Aerodynamics 95(9-11):1463-1475

Tang C, Han Y, Shen L et al (2020) Experimental study on urban wind environment influenced by adjacent high-rise building. J Civil Environ Eng 1(1):1-12

Tang J (2017) Wind tunnel test and CFD simulation study on strong wind characteristics of horn-mouth terrain bridge site. Xi'an Science and Technology University

Uchida T, Ohya Y (2003) Large-eddy simulation of turbulent airflow over complex terrain. J Wind Eng Ind Aerodynamics 91(1-2):219-229

Zhang M, LiY (2015) Field measurement of wind characteristics at bridge site in deep gorge with high altitude and high temperature difference. J China Highway 28(03):60-65

Zhang M, Li Y, Wang B, Ren S (2018) Numerical simulation of wind characteristics at bridge site considering thermal effects. Adv Struct Eng 21(9):1313-1326

\section{Publisher's Note}

Springer Nature remains neutral with regard to jurisdictional claims in published maps and institutional affiliations. 